\title{
Zoning as a Method for Assessing Geographic Factors for the Purposes of Sustainable Development of the Region
}

\author{
P.Ya. Baklanov, A.V. Moshkov, E.A. Ushakov* \\ Pacific Institute of Geography FEB RAS, Vladivostok, Russia \\ ${ }^{*}$ Corresponding author. Email: ushakov.tig.dvo@gmail.com
}

\begin{abstract}
Geographic factors are highlighted: geographic, including economic and geographic position; a combination of natural conditions, including extreme natural processes and hazardous phenomena; natural resources and their territorial combinations, as well as territorial structures of the economy and settlement. These factors play an important role in achieving sustainable regional development - as a stable development balanced in the economic, social and environmental spheres. Wherein, all geographical factors receive their spatial and substantive definiteness and completeness in the zoning system, within the boundaries of certain districts and their relations. It is offered to develop a combination of geographical zoning of large regions, including physical-geographical, natural-resource, functional, economic, socio-economic. Within the framework of certain types of zoning, more complete assessments of geographical factors and their influence on the sustainable development of regions are possible.
\end{abstract}

Keywords: geographical factors, natural conditions, natural resources, territorial structures, zoning, territory zoning, sustainable development.

\section{INTRODUCTION}

A large number of works are dedicated to the general problems of sustainable development of regions [1-6]. They often pay much attention to environmental factors and restrictions [1, 2, 4, 5]. However, in a broad sense, sustainable development is stable development balanced in the economic, social and environmental spheres $[1,3$, $5,6]$. Achievement of such a development in the region is greatly influenced by socio-economic, environmental, scientific and technical factors, as well as geographical ones. The latter ones include: geographical, including the economic and geographical position of a particular territory, district; natural conditions, including extreme and hazardous phenomena, natural resources and their distribution, the existing territorial structures of the economy and population. Wherein, in different districts, the combinations of such factors are significantly different, which requires special assessments $[1,3,5,6]$.

\section{STATEMENT OF THE PROBLEM}

Combinations of geographical factors (natural resources, economic and geographical position, achieved production and demographic potentials) largely determine the formation of stable territorial socioeconomic structures of various ranks: from economic centers to districts.

In the territory, there is always a spatial differentiation in distribution of favorable and negative geographical factors that significantly affect the diversity and location of elements of territorial socio-economic structures, including their cores, periphery, borders $[2,7$, $8,9,10,11,12]$. As a result of the combined action of favorable and negative geographical factors within the territories, territorial socio-economic structures of different ranks are formed, their necessary dynamics and stability in the process of socio-economic development are ensured. The links of such structures act as a basis for identifying districts, sub-district and economic centers $[13,14,15,16]$.

At the same time, identification and meaningful assessment of geographic factors is possible only within certain boundaries of the geographic space, that is, in certain previously identified districts. That is why, at the stage of developing sustainable development programs for the regional level, division and zoning of the territory 
is necessary, and in some cases, the adjacent water areas. What types of division of the territory, regionalization and zoning are necessary for these purposes - these problems have not been sufficiently studied and are the task of this article.

\section{MAIN CONTENT}

The following geographical factors are distinguished, which have a great influence on the sustainable development of the region.

1. Combinations of natural conditions, their spatial differentiation and variability over time. Features of the relief, soils, vegetation, climate and microclimate, on the one hand, largely determine the economic costs of formation and functioning the territorial socio-economic systems and their components, and on the other hand their reliability. This is especially influenced by the extreme natural processes and hazardous phenomena occurring in the region.

2. The geographical one, including the economic and geographical position of the region, firstly, determines the general type of natural conditions, and, secondly, interdistrict relations - both real and potential, possible ones. The region's access to the sea coast gives a special specificity to regional development. Wherein, there is wide access to sea transport, to use of marine natural resources.

3. Combinations of natural resources in the region, their location and the relationship of certain types. For the purposes of sustainable development, it is important to balance the use of territorial combinations of natural resources, including the most important for sustainable development - renewable ones. Therefore, it is necessary to identify real-life territorial combinations of natural resources. For these purposes, it is offered to conduct a natural resource zoning of territories, and in some cases - the adjacent water areas also. Such districts are based on allocation of territorial and aqua-territorial combinations of natural resources.

4. Territorial structures of economy and settlement formed in the region. To distinguish their more holistic formations, economic zoning is necessary, and in a more complete form - socio-economic ones.

As our study shows, all these geographical factors acquire their spatial definiteness and meaningfulness only in the system of geographical division of the territory and zoning. Wherein, zoning, on the one hand, gives the geographical factors spatial and substantive definiteness and completeness, and on the other hand, it determines interdistrict relations and interactions $[13,14$, $16]$.

Thus, the economic and geographical position of a certain territory acquires its definiteness only in the zoning system. Wherein, such properties of the EGP as the neighborhood with other districts, their centers and periphery, and, consequently, the potential of interdistrict connections and relations, can be established and evaluated in a strict form.

For a territory within a certain district, combinations of natural conditions, including extreme and hazardous phenomena, as well as territorial combinations of natural resources with their inter-resource links and relationships, can be identified and quantified. Finally, within the framework of a certain district, agglomeration processes and their potential in the established centers, nuclei of territorial structures of the economy and settlement can be more rigorously assessed. It shall be emphasized that it is precisely in the zoning system, primarily of the administrative-territorial one, that the coverage of the managerial factor and the completeness of information about the territory are achieved $[10,11,12,17,18]$.

All this provides a fairly complete meaningfulness of geographical factors and the possibility of their rigorous quantitative assessment.

In modern conditions, the most complete one is the administrative-territorial zoning. This is due to the fact that planning and regional management are included in the administrative districts, in their functioning and development. Taking this into account, it is advisable for the administrative districts of different levels to develop programs to achieve and maintain sustainable development. Such programs shall be based on the strict structuring of the district and allocation of its interrelated constituent parts and spatial sections (Fig. 1).

Each district allocated in the process of zoning, has its own specific features that determine its specialization, the current socio-economic situation and the prerequisites for achieving the sustainable development. The general combination of geographical factors in a certain territory of the district can create favorable preconditions for sustainable development, some of the geographical factors can also be limiting for sustainable development. An example of such limiting factors can be the natural and climatic conditions of the northern districts, or extreme natural processes (zones of earthquakes, tsunamis, floods, etc.).

It shall be noted that there are so-called underdeveloped or depressed territories in a number of economic districts. The latter are often determined by a combination of unfavorable factors and are supported by certain measures on the part of the authorities. In a number of cases, special programs are being developed to create new promising types of activities in such districts. It is also possible for them to join a more developed territory, which can bring them out of a depressive state at the expense of their resources. 


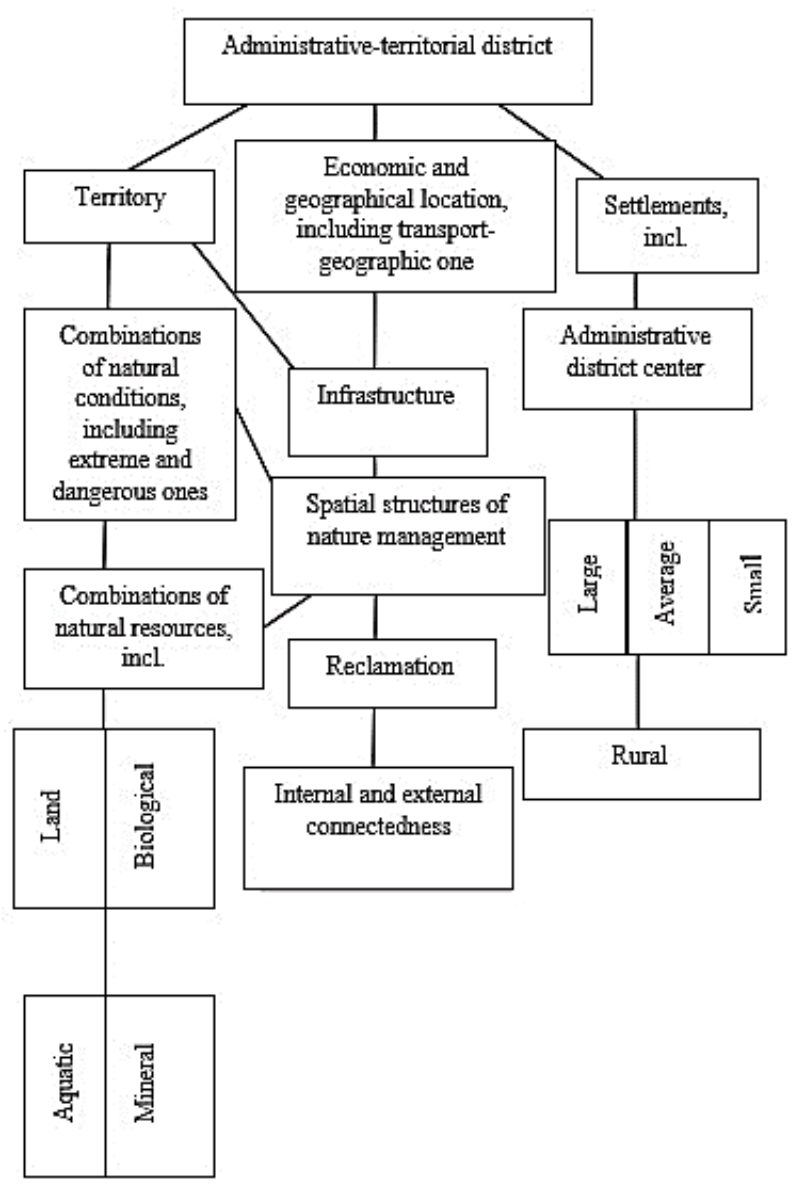

Figure 1 Separate components and spatial sections of the district

Settlements with a large population and a high level of socio-economic development are important for socioeconomic zoning. They constitute specific centers, the nucleus of socio-economic zoning. A particularly important role is played by large and big settlements, which concentrate a significant part of the population of the territory and its socio-economic potential. Socioeconomic centers of a lower rank are small towns and administrative centers of municipal districts. They often lag behind in their socio-economic development in relation to large and big cities. Many settlements are often small and have lower levels of socio-economic development. Some of these settlements may show signs of depression. In general, the administrative centers of districts (administrative-territorial at different levels) often have a great impact on the socio-economic situation of the entire district.

Economic zoning plays a special role in the administrative division of the country. Administrative division, considering economic zoning, shall contribute to the sustainable development of administrativeterritorial units (ATU).

It shall be noted that influence of administrative boundaries also affects the socio-economic state of the territory. In general, the socio-economic basis of the territory (including the municipal district) is created by two interrelated components - the natural resource base of the territory and the settlements located on it with their own economic basis and transport infrastructure, which is also connected with neighboring territories. Administrative boundaries create the general configuration of a given territory. Due to this, the economic and geographical position of the territory is formed, as well as the favorable and limiting factors of its development are singled out. Therefore, the basis of the administrative-territorial division shall be socioeconomic zoning.

An administrative-territorial unit (ATU) is a territory that is allocated by administrative boundaries at a certain management level (federal, regional, municipal), on which regional government bodies (executive and legislative) have been created, which manage the territory by establishing and observing local laws, collection of taxes and adoption of other standards. The hierarchy of ATUs at different levels is important, including their managerial functions and relevant bodies. An important characteristic of such districts is provision of their own resources, including financial ones.

In general, for the purposes of achieving and maintaining sustainable development of the region, the following system of geographical division of the territory and adjacent sea areas and zoning is offered.

1. Dividing the territory according to the degree of homogeneity of individual natural components, natural conditions - relief, soils, vegetation, climate, and etc.

2. Physico-geographical zoning and allocation of relatively integral geographic formations - landscapes, geosystems.

3. Natural resource zoning and allocation of territorial and aqua-territorial combinations of natural resources - as the main, most complete objects of assessment, planning, development and management of sustainable natural resources in the region. On this basis, zoning of the territory and allocation of areas with certain types of natural resource use and their restrictions are important.

4. Economic zoning and allocation of relatively integral territorial economic structures and systems, including considering the forecast options for their development. The natural resource basis of economic districts is formed by territorial combinations of natural resources. Therefore, economic zoning shall be based on natural resource zoning with the specification of boundaries, considering options for long-term spatial development.

5. Socio-economic zoning - with adjustment of the boundaries of economic zoning, considering the living conditions of the population and the various connectivity 
of individual settlements and territories, and their development prospects.

The subsequent imposition of these zoning grids and their interconnection are possible within the boundaries of larger regions, at the level of macroregions.

\section{CONCLUSION}

The combination of geographic factors plays a large role in the possibilities and options for achieving sustainable development in the region. For their more complete accounting and assessment, various types of division of the territory and zoning are required. Wherein, the combination of geographical factors obtains its spatial definiteness and structural and functional content. To reflect and evaluate them, it is necessary to build special regional GIS.

\section{REFERENCES}

[1] Transition to sustainable development: global, regional and local levels. Foreign experience and problems of Russia. KMK, 2002 p. 444.

[2] A.K. Tulokhonov, Baikal Regions: Problems of Sustainable Development. Nauka, 1999 p. 208.

[3] P.Ya. Baklanov, Far Eastern region of Russia: problems and prerequisites for sustainable development. Dalnauka, 2001 p. 144.

[4] Yu.I. Vinokurov, B.A. Krasnoyarova, V.I. Ovdien ko and et al., Sustainable development of the Siberian regions. Nauka, 2003 p. 240.

[5] Russia and its regions: integration potential, risks, ways of transition to sustainable development. KMK Scientific Publishing Association, 2012.

[6] Cui Wehong, P.Ya. Baklanov, Sustainable Development and cyclic economy informatization. "Science and Technology of China" Publishing House, 2009 p. 512.

[7] E.B. Alaev, Socio-economic geography: Conceptual-terminol. words. Mysl., 1983 p. 290.

[8] L. G. Osmolovskaya, The function of the border as a factor in the development of border regions and formation of cross-border regions. Bulletin of the Baltic Federal University 1 (2016) p. 45-54.

[9] V.A. Kolosov, M.V. Zotova, A.B. Sebentsov. Barrier function of Russian borders. Izvestiya RAN. Geographic series 5 (2016) pp. 8-20.

[10] V.E. Shuvalov, Geographic boundary as a factor of district formation. Geographic boundaries. Moscow State University, 1982 pp. 33-38.
[11] O.V. Tsvetkova, Borders and interregional relations in the political-territorial structure of Russia: modeling technologies. UlGU, 2016 p. 381.

[12] Borders and Transborders Process in Russia. Dalnauka, 2013 p. 250.

[13] P. Ya. Baklanov. On the theory of economic zoning ("theorem" on economic zoning). Regional studies 3 (2018) pp. 19-24.

[14] P. Ya. Baklanov. On the content and meanings of socio-economic zoning. Geographical Bulletin 3 (2018) pp. 24-30.

[15] A.V. Moshkov, Structural shifts in industrial production of the Pacific regions of Russia. Scientific notes of the Transbaikal State University 1 (2015) pp. 98-106.

[16] Socio-economic geography in Russia. Dalnauka, 2016 p. 326

[17] V.I. Blanutsa, Socio-economic zoning in the era of big data. Infra-M, 2018 p. 194.

[18] E.A. Ushakov. Approaches to assessing the impact of changes in the administrative-territorial division on the efficiency of the constituent entities of the Russian Federation. Multi-vector in the development of Russian regions: resources, strategies and new trends. IG RAS, 2017 pp. 333342. 